\title{
¿CiUdAdes en tRANSICIÓN? LaS NUEVAS DINÁMICAS MUNICIPALES Y LAS TRANSICIONES ECOSOCIALES
}

\section{Cities in transition? The new municipal dynamics and ecosocial transitions}

\author{
José Eduardo García Díaz
}

Fecha de recepción: 17-06 -2019 - Fecha de aceptación: 30-07-2019

Hábitat y Sociedad (ISSN 2173-125X), n. ${ }^{\circ}$ 12, noviembre de 2019, pp. 143-146.

http://dx.doi.org/10.12795/HabitatySociedad.2019.i12.10

\begin{abstract}
The book Ciudades en movimiento collects the achievements and reflects the contradictions in the new municipal policies of Spain. It also provides a description of 200 actions related to the eco-social transition.

In the text, we can appreciate the difficulties faced by municipalities when they intend to increase local resilience. The structural limits determine that, in many cases, programmed actions have a purely palliative nature, without producing deep changes in social dynamics in relation to problems such as resource depletion or climate change.
\end{abstract}

\section{Key words}

Ecosocial transition; Municipal policy; Sustainability; Local resilience; Ecological crisis

\section{Resumen}

El libro Ciudades en movimiento recoge los logros y refleja las contradicciones presentes en las nuevas políticas municipales de España. También aporta una descripción de 200 actuaciones relacionadas con la transición ecosocial.

En el texto podemos apreciar las dificultades que enfrentan los ayuntamientos cuando pretenden incrementar la resiliencia local. Los límites estructurales determinan que, en muchos casos, las acciones programadas tengan un mero carácter asistencial, sin llegar a producir cambios en profundidad en las dinámicas sociales en relación con problemas como el agotamiento de los recursos o el cambio climático.

\section{Palabras clave}

Transición ecosocial; Política municipal; Sostenibilidad; Resiliencia local; Crisis ecológica

1 Profesor titular, jubilado, de la Universidad de Sevilla, del área de conocimiento de "Didáctica de las Ciencias Experimentales", adscrita al Departamento de Didáctica de las Ciencias Experimentales y Sociales. E-mail: jeduardo@us.es 


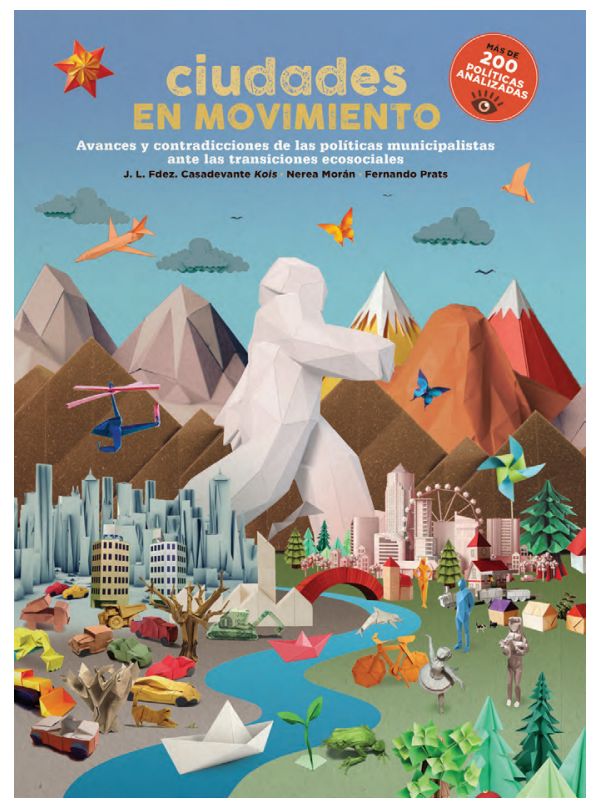

Fernández, José Luis; Morán, Nerea y Prats, Fernando (2018). Ciudades en movimiento. Avances y contradicciones de las políticas municipalistas ante las transiciones ecosociales. Madrid: CONAMA-FUHEM. [ISBN: 978-8495801-47-0]
El texto es el resultado del trabajo realizado por el "Foro de Transiciones" sobre las políticas municipales recientes de siete municipios representativos de las nuevas dinámicas municipales del estado español. Al respecto, se describen y analizan 200 experiencias y proyectos, lo que da pie a un conjunto de conclusiones de gran interés para evaluar el papel de los ayuntamientos en la transición ecosocial.

El libro está organizado en cuatro apartados. El primero, la introducción, incluye un interesante prólogo de Yayo Herrero, un capítulo que describe la metodología empleada y otro que ubica el trabajo realizado en una perspectiva ecosocial de corte decrecentista. En el segundo, se presentan las conclusiones; en el tercero se da voz a diferentes expertos que analizan algunos proyectos concretos; y en el último se ofrece un conjunto de fichas que recogen las experiencias investigadas.

El análisis se enmarca en un contexto teórico más general: los movimientos de transición como respuesta a la actual situación de emergencia planetaria y al choque civilizatorio con nuestros límites biofísicos. Y el cambio hacia una ciudad sostenible y autosuficiente. En relación con este planteamiento teórico, se proponen un conjunto de categorías de análisis, relativas tanto al metabolismo urbano (gestión de los recursos y de las emisiones) como a la planificación territorial (biorregiones que integran un mosaico de ecosistemas con diferente grado de humanización), la democracia (participación ciudadana, transparencia, descentralización y redes horizontales, control comunitario de la gestión...) o la desigualdad (políticas redistributivas e inclusivas, fortalecimiento de los servicios sociales y de los cuidados).

El libro constata las dificultades existentes para un cambio significativo de las actuaciones municipales, señalando una contradicción fundamental: mientras que el discurso institucional habla de sostenibilidad urbana y de mejora de la calidad de vida, la apuesta "real" es por estrategias económicas de corte desarrollista (especulación en el sector de la construcción, potenciación del turismo). Es decir, conviven las iniciativas singulares y parciales de regeneración y rehabilitación urbana, de defensa ante la turistificación y la gentrificación, de propuestas dirigidas a incrementar la resiliencia urbana (economía circular, social y solidaria, monedas sociales, autosuficiencia alimentaria, consumo saludable y sostenible...), con un núcleo central de actividades económicas convencionales. Esta contradicción queda bien reflejada en el siguiente párrafo del texto: tenemos “... ciudades condenadas como Penélope, mientras esperaba a Ulises, a deshacer por la noche lo que han tejido durante el día” (p. 64).

Esta contradicción se asocia a la carencia de un modelo explícito de ciudad "sostenible". Como indican los autores, no hay una visión de conjunto, un nuevo relato general que fundamente una ciudad resiliente, una estrategia a largo plazo: "la crisis ecosocial se encuentra en la periferia de la agenda municipalista, su nivel de prioridad comunicativa es bajo y, aquí parece el principal problema, su enmarcado elude tanto la gravedad de la situación como la urgencia temporal para lograr cambios radicales" (p. 71). En concreto, los "municipios del cambio" siguen esquivando la crisis ecológica, siguen sin apreciar el alcance y la profundidad de dicha crisis.

De hecho, si analizamos los logros reseñados en el libro desde una perspectiva de "estado de emergencia", podría decirse que se trata más de cambios superficiales, casi asistenciales, que de una transición ecosocial generadora de cambios estructurales que posibiliten un mayor ajuste a una situación de decrecimiento. 
Tal como se refleja en el texto, las mejoras se dan principalmente en determinados ámbitos en los que resulta más fácil introducir cambios, sin tocar el núcleo duro del sistema: la adopción de un discurso feminista y de "sostenibilidad", el tema de los cuidados, el desarrollo de algunas experiencias concretas y puntuales de economía social y solidaria, la movilidad y la disminución de la contaminación asociada al tráfico, la renaturalización de espacios degradados, la promoción de una alimentación saludable y sostenible, la mejora de servicios públicos y sociales, el apoyo a una vivienda social, el freno a la turistificación y gentrificación de los centros urbanos, las nuevas experiencias de democracia participativa, la mayor transparencia en la gestión, la lucha contra la pobreza energética, o las actuaciones compensatorias en zonas desfavorecidas.

Sin embargo, hay un menor avance en políticas de largo alcance y en medidas que incrementen la resiliencia ante un decrecimiento inevitable: sustitución de la economía neoliberal por una economía circular basada en el bien común, integración campo-ciudad y organización territorial en mosaico, autosuficiencia alimentaria (zonas verdes y huertos urbanos como propuesta de resiliencia y no solo como "entretenimiento"), educación en y para el decrecimiento...

La cuestión clave que se infiere de la lectura del libro es si los gobiernos locales tienen capacidad para revertir las pautas generales del crecimiento económico ilimitado. En el texto se aprecian dos posibles estrategias complementarias: por una parte, la lucha por conseguir más autonomía y capacidad de decisión local, por otra, el desarrollo de referentes de prácticas alternativas que posibiliten un mejor ajuste al decrecimiento.

Aunque el libro resulta muy útil para comprender el estado actual de las ciudades que pretenden ser sostenibles, no queda claro en el texto si las iniciativas y los proyectos reseñados están lo suficientemente imbricados en el tejido social como para resistir los cambios políticos coyunturales. Es decir, en qué medida son proyectos que realmente estén asumidos por la comunidad y no son solo iniciativas de una élite "progresista", de forma que si se pierde el gobierno municipal no se derrumbe la alternativa construida. En otros términos, falta una visión de conjunto en la que se analice tanto el desarrollo actual de las redes sociales como la coordinación entre estas redes y las propuestas institucionales.

Este es un tema central sobre el que merecería la pena seguir investigando. Es cierto que el texto nos ofrece una buena panorámica de los proyectos institucionales en marcha, con muchos datos y tablas en las que se puede ver con claridad qué temas son tocados por las políticas municipales de los distintos ayuntamientos considerados, así como una extensa reseña en formato fichas de las actuaciones analizadas. Pero falta, en la valoración de las experiencias, una profundización en dos aspectos: cómo de sólidas son las redes creadas (su imbricación con el tejido social) y en qué medida dichos proyectos suponen un cambio real hacia la resiliencia local.

Se echa en falta una perspectiva más crítica (en muchas de las fichas la valoración consiste en loar sin más la iniciativa municipal) y, sobre todo, un análisis más cualitativo en determinados ámbitos, en los que las variables cuantitativas o la propaganda institucional (de hecho, en muchas fichas se recoge sin ninguna valoración crítica la retórica de la sostenibilidad) no aportan mucho sobre el alcance de la iniciativa en cuestión. Si en política municipal se habla de un incremento de la lon- 
gitud de carriles bici, de una clara disminución de la contaminación atmosférica o de un aumento del número de viviendas sociales, estaríamos ante logros claros y evidentes. Pero esto no es igual cuando nos referimos a otros temas. Por ejemplo, en un proyecto municipal se puede incrementar el número de huertos urbanos y publicitarlo como un gran logro, pero, si dichos huertos no son realmente comunitarios (en muchos casos las concesiones a usuarios individuales llevan a una privatización encubierta) responden a motivaciones como el esparcimiento de personas mayores o no son ecológicos (es muy común en los huertos urbanos que no se respete el suelo como ecosistema, ni se cierre el ciclo de nutrientes, ni se fomente la biodiversidad), no deberíamos computar esa política municipal concreta como un "logro" en la transición ecosocial. Otro ejemplo: hay innumerables iniciativas municipales dirigidas a educar ambientalmente a la población que se encargan a empresas que en muchos casos siguen modelos didácticos obsoletos y/o se sustentan en el trabajo de educadores y educadoras mal pagados y poco formados, experiencias en las que se publicita como logro el gran número de personas participantes, sin considerar (ni evaluar) en qué medida se ha conseguido un cambio significativo de mentalidades y conductas.

Es decir, un análisis en profundidad de los logros de las nuevas políticas municipales debería de ir más allá de las estadísticas y de la propaganda institucional, con una evaluación más micro, con un estudio de campo que detecte en qué medida lo que se hace está siendo significativo para un incremento de la resiliencia local.

García Díaz, José Eduardo (2019). ¿Ciudades en transición? Las nuevas dinámicas municipales y las transiciones ecosociales. Hábitat y Sociedad, 12, 143-146.

$<$ http://dx.doi.org/10.12795/HabitatySociedad.2019.i12.10>

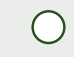

